\title{
Surface dependent electron and negative ion density in inductively coupled discharges
}

\author{
G. A. Hebner, M. G. Blain, T. W. Hamilton, C. A. Nichols and R. L. Jarecki \\ Sandia National Laboratories, Albuquerque NM 87185-1423
}

\begin{abstract}
Electron and negative ion density have been measured in a modified Applied Materials DPS metal etch chamber using gas mixtures of $\mathrm{BCl}_{3}, \mathrm{Cl}_{2}$ and $\mathrm{Ar}$. Measurements were performed for four different substrate types to examine the influence of surface material on the bulk plasma properties; aluminum, alumina, photoresist and 50 percent patterned aluminum / photoresist. Electron densities in the $\mathrm{Cl}_{2} / \mathrm{BCl}_{3}$ mixtures varied from 0.25 to $4 \times 10^{11} \mathrm{~cm}^{-3}$. Photodetachment measurements of the negative ion density indicate that the negative ion density was smaller than the electron density and that the electron to negative ion density ratio varied between 1 and 6 . The presence of photoresist had a dominant influence on the electron and negative ion density compared to alumina and aluminum surfaces. In most cases, the electron density above wafers covered with photoresist was a factor of two lower while the negative ion density was a factor of two higher than the aluminum or alumina surfaces.
\end{abstract}




\section{DISCLAIMER}

This report was prepared as an account of work sponsored by an agency of the United States Government. Neither the United States Government nor any agency thereof, nor any of their employees, make any warranty, express or implied, or assumes any legal liability or responsibility for the accuracy, completeness, or usefulness of any information, apparatus, product, or process disclosed, or represents that its use would not infringe privately owned rights. Reference herein to any specific commercial product, process, or service by trade name, trademark, manufacturer, or otherwise does not necessarily constitute or imply its endorsement, recommendation, or favoring by the United States Government or any agency thereof. The views and opinions of authors expressed herein do not necessarily state or reflect those of the United States Government or any agency thereof. 


\section{DISCLAIMER}

Portions of this document may be illegible in electronic image products. Images are produced from the best available original document. 


\section{Introduction}

Plasmas containing gas mixtures of boron trichloride and chlorine are used for a number of microelectronics applications including metal interconnect definition and III-V material processing. In such plasmas, the electron and negative ion density are fundamental plasma parameters that are influenced by a number of gas and surface reactions. For example, the formation of negative ions is an important electron loss mechanism. At a more fundamental level, electron and negative ion interactions can alter the electron energy distribution function, affect the spatial distribution of the plasma potential, and by charge neutrality, influence the total positive ion charge density. This in turn can impact the ion flux and ion energy to the wafer surface. Thus, electron and negative ion density are important parameters, and should be measured as an aid to improved understanding of discharges used in IC fabrication and for benchmarking numerical models.

Recently, we reported electron and negative ion measurements in a Gaseous Electronics Conference (GEC) rf reference cell that had been modified with an inductive plasma source. ${ }^{1,2}$ That investigation showed that the negative ion density was on the order of the electron density and that the negative ion spatial distribution was relatively uniform. In addition, surface material was shown to have a major influence on the negative ion density. When the stainless steel wafer surface was covered by a silicon wafer, the negative ion density decreased a factor of two, despite a constant electron density. Since a major formation mechanism for the negative ion is dissociative attachment, $\mathrm{Cl}_{2}+\mathrm{e}^{-} \rightarrow$ $\mathrm{Cl}^{-}+\mathrm{Cl}^{3-5}$ and the $\mathrm{Cl}_{2}$ density is relatively low due to a high degree of dissociation, ${ }^{6,7}$ any small change in the $\mathrm{Cl}_{2}$ density should be reflected in the $\mathrm{Cl}^{-}$density. Computational 
predictions have shown that the negative ion density is sensitive to the rate of surface recombination for conversion of atomic chlorine to molecular chlorine. ${ }^{3-5}$ In addition, recent measurements of the surface recombination rates for $\mathrm{Cl}$ to $\mathrm{Cl}_{2}$ have show a wide range of surface recombination rates, depending on surface material and temperature. ${ }^{8}$

This work extends our previous measurements to a commercial etch tool, the Applied Materials DPS metal etch system. To directly examine the influence of surface material on the bulk plasma parameters of electron and negative ion density, a number of surface materials were used. In addition to measuring fundamental plasma parameters in the DPS chamber, comparison of the measurements obtained in the two very different discharge geometries (GEC and DPS) provides insight into the influence of reactor material, geometry, surface coverage and operating conditions. These measurements were also used to provide data essential to effective benchmarking of computer models and the demonstration of a validated, geometry independent, set of chemical mechanisms to model aluminum etching by chlorine radicals. ${ }^{4}$

\section{Experimental configuration}

The experiments were performed in an Applied Materials DPS metal etch chamber that had been modified for enhanced diagnostic access. The modification, provided by Applied Materials, consisted of a number of additional diagnostic access ports that were machined into the standard upper chamber assembly. As shown in Fig. 1, provision was made for seven 1.7 and 2.2 inch diameter windows at a number of points around the chamber. When the diagnostic access to the plasma region above the $200 \mathrm{~mm}$ diameter wafer was not required, the windows were replaced with anodized aluminum inserts which 
were flush with the inside of the etch chamber wall. The chamber walls were anodized and the chamber dome was alumina. The balance of the process chamber, platform, gas handling and rf system were standard commercial product. Extensive measurements of the metal etch parameters of the tool with and without the window plugs indicated that the windows did not perturb the etch rate or the uniformity.

Line integrated electron density was measured using a microwave interferometer, while the negative ion density was inferred from a laser photodetachment measurement. The equipment and experimental configuration were very similar to that used to measure the electron and negative ion density in a laboratory research reactor, a Gaseous Electronics Conference (GEC) if reference reactor that has been modified to include an inductively coupled plasma source. ${ }^{1,2}$ The microwave interferometer operated at $80 \mathrm{GHz}$, and standard, high gain horns were used to transmit the microwaves through the plasma. The horn antenna alignment was optimized first for transmitted power and then a dielectric rod was used to map the radiation pattern, or microwave beam size, in the chamber. The microwave and photodetaching laser beam were positioned approximately $4 \mathrm{~mm}$ above the wafer surface. To reduce the influence of multipath reflections from the chamber walls and the wafer surface, the horns were rotated to place the electric field parallel to the wafer surface. Multipath interference due to reflection off the wafer surface was checked by lowering the wafer chuck approximately six inches from the process position to the wafer load position. When properly aligned, the difference in transmitted power with and without the wafer chuck in the process position was less than two percent. Multipath interference due to wall reflection was probed by moving a 2 inch wide by 0.25 inch thick dielectric slab along the chamber walls. After optimizing the horn position and 
orientation, a change of less than five percent was measured in the relative phase as the dielectric slab was moved around the chamber wall indicating multipath interference due to microwave wall scattering was small. Based upon ion saturation current probe measurements in the DPS chamber for typical operating conditions, the line integrated electron density measured using the microwave interferometer was converted to a peak electron density in the center of the plasma. In most cases, the ion saturation current was uniform with an approximate diameter of $25 \mathrm{~cm}$.

Photodetachment of electrons from $\mathrm{Cl}^{-}$was performed with a frequencyquadrupled Nd:YAG laser $(266 \mathrm{~nm})$ with typical pulse energy of $35 \mathrm{~mJ}$ at a $10 \mathrm{~Hz}$ repetition rate. The experimental setup and data reduction has been previously discussed. ${ }^{1,2}$ Briefly, to convert the measured excess electron density produced by photodetachment to an absolute negative ion density, several calibration factors must be utilized. First, the spatial distribution of the microwave probe beam must be determined. Second, the spatial energy distribution of the photodetaching laser should be uniform or measured. Third, each photon that traverses the plasma may not photodetach an electron from $\mathrm{Cl}^{-}$. A fractional photodisassociation efficiency must be calculated from the measured cross section. ${ }^{9}$ For the laser energy used in this experiment, approximately 35 percent of the $\mathrm{Cl}^{-}$was photodetached and the excess electron density was linear in laser energy. Finally, the microwave interferometer and amplifiers must be calibrated. The total uncertainty of these calibrations results in a factor of two uncertainty in the absolute $\mathrm{Cl}^{-}$number density. However, in any given data set (one plot), the relative density variation was reproducibly \pm 10 percent. 
The identity of the negative ions detected in these experiments is believed to be $\mathrm{Cl}^{-}$. In our previous measurements of $\mathrm{Cl}_{2} / \mathrm{BCl}_{3} / \mathrm{Ar}$ containing plasmas in the $\mathrm{GEC}$ discharge chamber, the wavelength of the Nd:YAG laser ( 266 or $355 \mathrm{~nm}$ ) was varied to identify the negative ion. ${ }^{2}$ The energy required to photodetach an electron from $\mathrm{Cl}^{-}$is $3.6 \mathrm{eV}$ (341 $\mathrm{nm}$ ) and from $\mathrm{Cl}_{2}{ }^{-}$is $2.5 \mathrm{eV}(496 \mathrm{~nm}) .^{10}$ The energy of the photon at $266 \mathrm{~nm}$ is $4.7 \mathrm{eV}$, well above the energy required for photodetachment of either $\mathrm{Cl}_{2}^{-}$or $\mathrm{Cl}^{-}$. To differentiate between $\mathrm{Cl}^{-}$and $\mathrm{Cl}_{2}^{-}$, the third harmonic of the Nd:YAG laser $(355 \mathrm{~nm}, 3.5 \mathrm{eV})$ was used. For the $266 \mathrm{~nm}$ radiation, a large signal was observed corresponding to the detachment of electrons from $\mathrm{Cl}^{-}$. This photodetachment signal was characterized by a very sharp rise time, corresponding to the rise time of the laser pulse. The signal for $355 \mathrm{~nm}$ radiation was much smaller despite the five times larger pulse energy, and did not have a rise time characteristic of a photodetachment process, but rather is more characteristic of an optogalvanic signal. ${ }^{11}$ From this we concluded that the density of $\mathrm{Cl}_{2}^{-}$in this discharge was very small compared to the density of $\mathrm{Cl}^{-}$. In order to estimate the maximum $\mathrm{Cl}_{2}{ }^{-}$ density that the $355 \mathrm{~nm}$ signal corresponded to, the photodetachment cross section for $\mathrm{Cl}_{2}^{-}$ must be known. This cross section has not yet been measured, but would not be expected to differ from that of $\mathrm{Cl}^{-}$by more than a factor of 10 . An estimate of the upper bound for $\mathrm{Cl}_{2}{ }^{-}$density in this discharge was $1.3 \times 10^{8} \mathrm{~cm}^{-3}$, approximately three orders of magnitude smaller than the $\mathrm{Cl}^{-}$density measured. Thus, we concluded that compared to $\mathrm{Cl}^{-}, \mathrm{Cl}_{2}{ }^{-}$is not an important species in $\mathrm{Cl}_{2}$ ICP discharges. Similar arguments can also be made for $\mathrm{BCl}_{\mathrm{x}}$. While the photodetachment cross section or thresholds for $\mathrm{BCl}_{\mathrm{x}}{ }^{-}$are unknown, our previous measurements suggest that these negative ions may not have a significant density. Finally, recent mass spectroscopy measurements performed during etching of aluminum 
with photoresist coverage indicate the presence of a number of $\mathrm{C}_{\mathrm{x}} \mathrm{Cl}_{\mathrm{y}}$ species which may form negative ions. ${ }^{12}$ Since the details of the radical negative ion formation, loss, and photodetachment processes for the photoresist etch and sputter products are completely unknown, we have assumed, based upon extrapolation for our previous measurement, that $\mathrm{Cl}^{-}$is the majority negative ion.

The dominant formation mechanism for $\mathrm{Cl}^{-}$from $\mathrm{Cl}_{2}$ is dissociative attachment, $\mathrm{Cl}_{2}$ $+\mathrm{e}^{-} \rightarrow \mathrm{Cl}^{-}+\mathrm{Cl}$, while in $\mathrm{BCl}_{3}$ containing gas mixtures the reaction $\mathrm{BCl}_{3}+\mathrm{e}^{-} \rightarrow \mathrm{Cl}^{-}+\mathrm{BCl}_{2}$ is believed to be important. ${ }^{4}$ Since the $\mathrm{Cl}_{2}$ density is known to be relatively low due to a high degree of disassociation, ${ }^{6,7}$ any small change in the $\mathrm{Cl}_{2}$ density should be reflected in the $\mathrm{Cl}^{-}$density. While the disassociation fraction for $\mathrm{BCl}_{3}$ is unknown in this geometry, it is also believed to be well dissociated and providing $\mathrm{Cl}$ to the gas phase that may recombine on surfaces to form $\mathrm{Cl}_{2}$, a source term for $\mathrm{Cl}^{-}$formation. Recent computational predictions have shown that the negative ion density is sensitive to the rate of surface recombination for conversion of atomic chlorine to molecular chlorine. ${ }^{4}$ In addition, measurements of the surface recombination rate for $\mathrm{Cl}_{2}$ formation from $\mathrm{Cl}$ have shown that the rate is a strong function of surface and temperature. ${ }^{8}$

In order to observe the impact of surface material, four different surfaces, representative of typical processing surfaces, were used. Surfaces included a aluminum, alumina, blanket photoresist (Shipley Apex Deep UV) and 50 percent open area photoresist patterned aluminum. The $\mathrm{Al}$ and $\mathrm{Al}_{2} \mathrm{O}_{3}$ wafers were solid materials that had been machined to wafer dimensions. During processing of the photoresist / $\mathrm{Al}$ wafers, optical endpoint (Al atomic emission at $396 \mathrm{~nm}$ ) was used to insure the measurements were obtained during etching or after endpoint. The blanket photoresist wafers were 
examined before and after the measurements to insure the photoresist was not removed or bubbled during the measurement time. Alumina was included in the material set since it is a common reactor material (e.g. the dome and some interior surfaces) and it is thought to be relatively unreactive.

Measurements were obtained for a minimum of 18 standard tool settings covering a wide range of source power, pressure, bias, flow rate, $\mathrm{Cl}_{2}$ to $\mathrm{BCl}_{3}$ ratio, and argon addition. Tool parameters were varied about a nominal center operating point of $1100 \mathrm{~W}$ source power, $200 \mathrm{~W}$ bias power, $10 \mathrm{mTorr}$ pressure, $\mathrm{Cl}_{2}$ flow rate of $100 \mathrm{sccm}$ and a $\mathrm{BCl}_{3}$ flow rate of $40 \mathrm{sccm}$. Typically, measurements were obtained after allowing the plasma to stabilize for 10 seconds and required approximately 20 seconds to complete. Depending on the plasma conditions, typical aluminum etch times were on the order of 40 to 65 seconds. Negative ion densities were not obtained using the $\mathrm{Al} /$ photoresist patterned wafers due to the rapid removal time for the aluminum compared with the longer time required to average the data for the photodetachment measurement. To insure that the tool conditions had not significantly shifted, several tool settings and surfaces were repeated multiple times, for example at the beginning and end of each data set. In general, the electron and negative ion measurements were reproducible to within 7 percent from day to day. Of particular note, the electron density was reproducible to within 7 percent even after a wet chamber clean using $\mathrm{HCl}$ and water.

Using the aluminum / photoresist patterned wafers, the electron density measured before and after etch endpoint varied by less than five percent. Process endpoint was determined by monitoring the plasma induced optical emission of the $396 \mathrm{~nm}$ atomic aluminum line. However, we did observe an approximately 20 percent transient "glitch" in 
the electron density several seconds before the optical endpoint signal started to decrease. The transient change typically lasted less than a second, and the microwave interferometer recovered back to the value observed during aluminum etching. The origin of the transient change is unclear but may be related to the a transient change in the process chemistry at endpoint and / or a transient change in the power coupling due to the matching system reoptimizing.

\section{Results and Discussion}

As the if power in the induction coil was increased, the electron and negative ion density increased, independent of the reactor surface. As shown in Fig. 2, the electron density varied between 0.5 and $3.6 \times 10^{11} \mathrm{~cm}^{-3}$ while the negative ion density varied between 0.15 and $1.0 \times 10^{11} \mathrm{~cm}^{-3}$. In general, the electron density above the aluminum and alumina surfaces were significantly greater than the density above the photoresist containing surfaces. However, the negative ion density above the photoresist surface was generally higher than the aluminum or alumina surfaces.

The influence of different surfaces and possibly gas phase chemistry is evident in these measurements. The introduction of photoresist or its byproducts into the gas phase could be expected to modify the gas phase chemistry in addition to changing the surface reaction mechanisms. Wafers with photoresist on the surface had a significantly lower electron density than the reactive $\mathrm{Al}$ surface and the nominally unreactive alumina surface. In addition, the close agreement between the blanket photoresist wafer and the Al / PR patterned wafer suggests that any photoresist has a dominant influence on the electron density. It is somewhat surprising that the electron density with the aluminum and alumina 
surface is comparable. For a 50 percent open area, aluminum / photoresist patterned wafer and a nominal aluminum etch rate of $1.2 \mu \mathrm{m} / \mathrm{min}$, the gas flux of etch products off the surface and into the gas phase is on the order of $42 \mathrm{sccm}$. For these etch conditions, the total reactive gas flow from the bottles was $140 \mathrm{sccm}$. However, this significant etch product gas flow does not significantly alter the electron density when compared with a nominally unreactive alumina surface.

With regards to the negative ion density, the aluminum and alumina surfaces have the highest electron density but the lowest negative ion density. For these surfaces, the electron to negative ion ratio, $\mathrm{N}_{\mathrm{e}} / \mathrm{N}$, was 5 while the photoresist surface had a $\mathrm{N}_{\mathrm{e}} / \mathrm{N}$ ratio of 1.2. These differences are likely due to different surface recombination rates for the formation of $\mathrm{Cl}_{2}$ and the subsequent dissociative attachment formation of $\mathrm{Cl}^{-}$. In addition to changes in the surface recombination rate, other possible mechanisms include the unknown influence of the sputtered photoresist and / or photoresist $\mathrm{C}_{\mathrm{x}} \mathrm{Cl}_{\mathrm{y}}$ etch products on the gas phase chemistry and ionization rate.

The linear increase in negative ion density with a linear increase in electron density was previously observed in an ICP source containing only $\mathrm{Cl}_{2}$ or $\mathrm{BCl}_{3}{ }^{1,2} \mathrm{~A}$ one to one increase in the negative ion density with the electron density would be expected if dissociative attachment was the major negative ion formation process and the electron temperature and loss processes were constant. However, in previous measurements of the electron and negative ion density in mixtures of $\mathrm{Cl}_{2} / \mathrm{BCl}_{3}$ in the GEC ICP system, the electron density increased linearly with rf power but the negative ion density was constant. ${ }^{2}$ These differences between the GEC and DPS systems can be attributed to the different discharge geometries. In the GEC ICP, the discharge is well confined by the cell 
geometry and the measurement volume is in the center of the discharge. While the power input per unit volume is approximately equal for the two chambers, in the DPS chamber, the discharge volume is considerably higher and the measurement only samples those electrons and negative ions above the wafer. Due to their mass, negative ions are trapped in the center of the discharge and will tend to accumulate in the regions were the plasma potential is highest. In addition, the peak electron density tends to be in the region near the induction coil. In the GEC ICP, the plasma potential and electron density always peaks in the center of chamber, where the measurements were performed. However, in the larger DPS chamber, it is possible for the location of the maximum electron density, plasma potential and hence the negative ion density, to move relative to the measurement position. This argument is supported by recent $2 \mathrm{D}$ calculations of the GEC ICP and DPS geometry that show the maximum in the plasma potential moving closer to the induction coils as the power and pressure are raised. ${ }^{13}$

As the rf bias power was increased from 0 to $300 \mathrm{~W}$, the electron density was relatively constant for aluminum and alumina substrates (Fig. 3). For the surfaces that contained photoresist, the electron density decreased somewhat when the bias power was increased from 0 to $100 \mathrm{~W}$ and then was constant up to bias powers of $300 \mathrm{~W}$. The change in electron density from 0 to $100 \mathrm{~W}$ may be due to a change in the etch and / or sputtering rate of the photoresist with and without an If bias. Irrespective of the surface material, for biases above $100 \mathrm{~W}$, the electron density was independent of bias power. The apparent independence of the electron density from bias power is consistent with a number of previous measurements in a wide variety of ICP systems. Above the aluminum and alumina surfaces, the negative ion density was constant with increased bias power, 
consistent with the constant electron density. However, the negative ion density above the photoresist coated surface appears to slightly increase. The increase may be due to etched or sputtered material changing the negative ion formation rate by slightly changing the atomic chlorine surface recombination rate or the electron temperature. In addition, we can not rule out the possible contribution of additional, currently unknown, negative ion species produced by photoresist etch products. As with the power variation discussed above, the negative ion density was highest above the photoresist coated wafers.

Increasing the total chamber pressure from 5 to $30 \mathrm{mTorr}$ resulted in a factor of two decrease in the electron density for all surface materials (Fig. 4). However, over this same pressure range, the negative ion density was roughly constant. In our previous measurements in mixtures of $\mathrm{Cl}_{2}$ and $\mathrm{BCl}_{3}$ in the $\mathrm{GEC}$ chamber, the electron density was constant with increasing pressure while the negative ion density increased. ${ }^{2}$ In that case, it was argued that increasing the pressure with a constant electron density would result in an increased negative ion density since the $\mathrm{Cl}_{2}$ density would increase (assuming a constant disassociation fraction). These measurements in the DPS chamber are not inconsistent with that argument. Due to the larger discharge chamber in the DPS system, the location of the electron density maximum may be moving closer to the if coils and out of the measurement position. Thus the decreasing electron density and the increased pressure may be approximately balancing each other to produce an approximately constant negative ion density above the wafer surface.

As the $\mathrm{Cl}_{2}$ to $\mathrm{BCl}_{3}$ ratio was changed from pure $\mathrm{Cl}_{2}$ to pure $\mathrm{BCl}_{3}$, the electron density decreased for the $\mathrm{Al}$ and $\mathrm{Al}_{2} \mathrm{O}_{3}$ surfaces while it was constant to slightly increasing for the surfaces containing photoresist (Fig. 5). For these measurements, the total flow 
rate was held constant at $140 \mathrm{sccm}$ and the $\mathrm{Cl}_{2} / \mathrm{BCl}_{3}$ ratio was changed. In all cases, the negative ion density decreased as the gas ratio was changed. For the case of the aluminum surface, the decrease in the negative ion density is consistent with the decrease in electron density. However, the decrease in the negative ion density above the photoresist wafers was opposite of what would be expected for an increasing electron density and a simple $\mathrm{Cl}_{2}$ dissociative attachment negative ion formation mechanism. This trend strongly indicates additional negative ion formation mechanisms may be important. The additional reactions may be a combination of influences such as a change in the electron temperature, molecular chlorine density due to additional gas or surface reactions, or formation of other negative ions from the photoresist sputter and etch products. Looking at the data for the alumina surface, the initial large decrease in the negative ion density when the $\mathrm{BCl}_{3}$ was added to pure $\mathrm{Cl}_{2}$, without an associated drop in the electron density, may indicate that the alumina surface reactions are different from those on either aluminum or photoresist surfaces. Although we cannot rule out a change in the gas phase negative ion production mechanisms, the decrease above alumina may also be due to $\mathrm{BCl}_{3}$ covering part of the surface and reducing the number of available sites for $\mathrm{Cl}$ recombination. Mass spectroscopy data shows that the presence of $\mathrm{BCl}_{3}$ can suppress ion assisted etching of aluminum by chlorine. ${ }^{12}$ Whatever the exact mechanism, in cases where it may be important to maximize the negative ion density, alumina may not be the best surface material.

These measurements are in contrast to our previous measurements in the GEC chamber that showed that the electron density was independent of the $\mathrm{Cl}_{2} / \mathrm{BCl}_{3}$ ratio. ${ }^{2}$ In addition, the negative ion density decreased as the gas mixture was changed from pure $\mathrm{Cl}_{2}$ 
to pure $\mathrm{BCl}_{3}$. In that case, we suggested that the volumetric recombination loss rate would change as the dominant positive ions changed from $\mathrm{Cl}^{+}$and $\mathrm{Cl}_{2}{ }^{+}$to $\mathrm{Cl}^{+}$and $\mathrm{BCl}_{2}^{+}$as the gas ratio was varied. In addition, the dominant negative ion formation mechanism would likely change as the $\mathrm{Cl}_{2} / \mathrm{BCl}_{3}$ ratio changed, although the exact production mechanism for $\mathrm{Cl}^{-}$from $\mathrm{BCl}_{3}$ or its disassociation products, $\mathrm{BCl}_{\mathrm{x}}$, is unknown. In the DPS chamber, those mechanisms are likely to be also important but direct interpretation is difficult due to the possibility of the spatial movement of the maximum plasma density in the larger chamber.

As shown in Fig. 6, decreasing the total flow rate from the nominal $140 \mathrm{sccm}$ to 35 $\mathrm{sccm}$ resulted in an increase in the electron density above the alumina substrate and a decrease above the aluminum substrate. As the total flow rate was decreased, the surface reaction rates and the amount of etch product that is recycled back into the plasma and dissociated will change. As a result, one might expect the electron density to change in the case of the aluminum etch. The opposite trend above the alumina substrate supports the hypothesis proposed above that alumina is playing an important, but unknown role in the gas phase chemistry. For the case of the blanket photoresist wafers, the electron density was independent of flow rate and a factor of two lower than the density above the aluminum substrate, as observed in all the previous data. The observation that the electron density above the $\mathrm{Al}$ / photoresist patterned wafers is constant with flow rate and very comparable to the blanket photoresist wafers indicates that the electron density scaling is dominated by the presence of photoresist. The exposed aluminum and its etch products have minor impact on the total charged particle density. 
As the total flow was decreased, the negative ion density was approximately constant for the photoresist and alumina surfaces while the negative ion density decreased slightly above the aluminum surface. The trends in the negative ion density above the aluminum surface and the photoresist surface are consistent with their respective changes in electron density. The relatively constant negative ion density above the alumina surface, despite a 40 percent change in the electron density also supports the hypothesis of important alumina / plasma species interactions.

The influence of argon addition on $\mathrm{Cl}_{2} / \mathrm{BCl}_{3}$ metal etch mixtures, typical of overetch recipes, is shown in Fig. 7. For this set of measurements, the nominal tool settings were changed to $900 \mathrm{~W}$ source power, $185 \mathrm{~W}$ bias power, $\mathrm{Cl}_{2}$ flow rate of 60 sccm and a $\mathrm{BCl}_{3}$ flow rate of $30 \mathrm{sccm}$. Argon flow rate was 0,25 and $50 \mathrm{sccm}$ and pressure was maintained at $7 \mathrm{mTorr}$ for all conditions. As argon was added to the plasma, the electron and negative ion density were constant for most surface conditions. The only exceptions occurred at the highest argon flow rate; above the aluminum surface the electron density increased and above the photoresist wafer, the negative ion decreased. In general, the constant electron and negative ion density with argon addition were consistent with our previous measurements in the GEC chamber that showed argon addition had a minimal impact on the bulk plasma species densities. ${ }^{2}$ The only exception to this observation was when the $\mathrm{Ar} / \mathrm{Cl}_{2}$ ratio was greater than one. ${ }^{2.14}$

IV. Summary

Electron and negative ion density have been measured in a modified Applied Materials DPS plasma etch chamber using gas mixtures of $\mathrm{BCl}_{3}, \mathrm{Cl}_{2}$ and $\mathrm{Ar}$. 
Photodetachment measurements of the negative ion density indicate that the electron to negative ion density ratio varied between 1 and 6 . Measurements were performed for four different substrate types to examine the influence of surface material on the bulk plasma properties; aluminum, aluminum oxide, photoresist and 50 percent aluminum / photoresist. The presence of photoresist had a dominant influence on the electron and negative ion density, overwhelming the influence of the aluminum and its etch products. In most cases, the electron density above wafers covered with photoresist were a factor of two lower while the negative ion density was a factor of two higher than the aluminum or alumina surfaces. Although alumina was originally added to the study to provide a nominally less chemically reactive surface than blanket aluminum, these measurements show that alumina can have a significant influence on the plasma composition, particularly in the presence of $\mathrm{BCl}_{3}$. The exact nature of the plasma interaction with the alumina and or its etch products are unknown, although the alumina etch products, possibly $\mathrm{BO}_{\mathrm{x}}$ or $\mathrm{AlCl}_{\mathrm{x}}$ could be modifying the gas phase chemistry.

In general, the trends observed in the DPS chamber and our previous measurements in the GEC were in reasonable agreement. The major discrepancies can be reasonably attributed to the larger discharge volume and larger surface to volume ratio in the DPS chamber, and the possibility that the plasma composition can vary through out the entire volume. In the GEC chamber measurements, the plasma is well confined in the measurement volume but the measurements in the DPS chamber monitor the plasma composition only above the wafer.

\section{Acknowledgments}


The authors have greatly benefited from numerous discussions with $\mathbf{P}$.

Loewenhardt, P. Ionov, D. Ma, E. Meeks, P. Ho, S. Choi, P. Miller, M. Riley, J.

Woodworth, M. Kushner, V. Donnelly, and E. Lee. The authors acknowledge the

technical assistance of $\mathrm{P}$. Chavez. This work was performed at Sandia National

Laboratories and supported by SEMATECH, Applied Materials, and the United States

Department of Energy (DE-AC04-94AL85000).

Sandia is a multiprogram laboratory

operated by Sandia Corporation, a

Lockheed Martin Company, for the

United States Department of Energy

under contract DE-AC04-94AL85000. 


\section{References}

1. G. A. Hebner, J. Vac. Sci. Technol. A 14, 2158 (1996).

2. C. B. Fleddermann and G. A. Hebner, J. Vac. Sci. Technol. A 15, 1955 (1997).

3. R. A. Stewart, P. Vitello, D. B. Graves, E. F. Jaeger and L. A. Berry, Plasma Sources Sci. Technol. 4, 36 (1995).

4. E. Meeks, P. Ho, A. Ting and R. J. Buss, J. Vac. Sci. Technol. A 16, 2227 (1998).

5. R. S. Wise, D. P. Lymberopoulos, D. J. Economou, Appl. Phys. Lett. 68, 2499 (1996).

6. R. M. Forrister and H. M. Anderson, 48th Gaseous Electronics Conference, Berkeley CA, October 9 - 13, 1995, paper EA-8.

7. M. V. Malyshev, V. M. Donnelly, A. Kornblit, N. A. Ciampa, J. Appl. Phys. 84, 137 (1998).

8. G. P. Kota, J. W. Coburn and D. B. Graves, J. Vac. Sci. Technol. A 16, 270 (1998).

9. A. Mandl, Phys. Rev. A 14, 345 (1976).

10. H. M. Rosenstock, K. Draxl, B. W. Steiner, and J. T. Herron, J. Phys. Chem. (Ref. Data) 6, supp. 1, 1977.

11. K. E. Greenberg, G. A. Hebner, and J. T. Verdeyen Appl. Phys. Lett. 44, 299 (1984).

12. M. G. Blain and R. L. Jarecki, unpublished.

13. S. Choi, P. Ho, E. Meeks, private communication.

14. G. A. Hebner and P. A. Miller, submitted to J. Appl. Phys. 


\section{Figure captions}

Fig. 1 Top and side views of the DPS chamber showing the location of the seven access ports in the modified upper etch chamber. The drawing is not to scale and the majority of the microwave interferometer is not shown.

Fig. 2 Electron (a) and negative ion (b) density as a function of source power for several wafer surface materials. The aluminum surface is denoted by $\mathrm{Al}(\boldsymbol{\theta})$. The alumina surface is denoted by AlO $(\bullet)$. The $50 / 50$, aluminum / photoresist patterned surface is denoted by $\mathrm{Al} / \mathrm{PR}(\boldsymbol{\nabla})$. The blanket photoresist surface is denoted by PR (⿴). The bias power was $200 \mathrm{~W}$, pressure was $10 \mathrm{mTorr}, \mathrm{Cl}_{2}$ flow rate was $100 \mathrm{sccm}$ and the $\mathrm{BCl}_{3}$ flow rate was $40 \mathrm{sccm}$.

Fig. 3 Electron (a) and negative ion (b) density as a function of wafer bias power for several wafer surface materials. The aluminum surface is denoted by $\mathrm{Al}(\bullet)$. The alumina surface is denoted by $\mathrm{AlO}(\bullet)$. The $50 / 50$, aluminum / photoresist patterned surface is denoted by $\mathrm{Al} / \mathrm{PR}(\nabla)$. The blanket photoresist surface is denoted by PR (耳). The source power was $1100 \mathrm{~W}$, pressure was $10 \mathrm{mTorr}, \mathrm{Cl}_{2}$ flow rate was $100 \mathrm{sccm}$ and the $\mathrm{BCl}_{3}$ flow rate was $40 \mathrm{sccm}$.

Fig. 4 Electron (a) and negative ion (b) density as a function of chamber pressure for several wafer surface materials. The aluminum surface is denoted by $\mathrm{Al}(\boldsymbol{\Theta})$. The alumina surface is denoted by AlO $(\diamond)$. The $50 / 50$, aluminum / photoresist patterned surface is denoted by $\mathrm{Al} / \mathrm{PR}(\boldsymbol{\nabla})$. The blanket photoresist surface is denoted by PR ( $\square$ ). The source power was $1100 \mathrm{~W}$, bias power was $200 \mathrm{~W}, \mathrm{Cl}_{2}$ flow rate was $100 \mathrm{sccm}$ and the $\mathrm{BCl}_{3}$ flow rate was $40 \mathrm{sccm}$. 
Fig. 5 Electron (a) and negative ion (b) density as a function of $\mathrm{Cl}_{2} / \mathrm{BCl}_{3}$ ratio for several wafer surface materials. The aluminum surface is denoted by $\mathrm{Al}(\boldsymbol{)})$. The alumina surface is denoted by $\mathrm{AlO}(\bullet)$. The $50 / 50$, aluminum / photoresist patterned surface is denoted by $\mathrm{Al} / \mathrm{PR}(\boldsymbol{\nabla})$. The blanket photoresist surface is denoted by PR (1). The source power was $1100 \mathrm{~W}$, bias power was $200 \mathrm{~W}$, pressure was 10 mTorr, total flow rate was $140 \mathrm{sccm}$.

Fig. 6 Electron (a) and negative ion (b) density as a function of total flow rate for several wafer surface materials. The aluminum surface is denoted by $\mathrm{Al}(\bullet)$. The alumina surface is denoted by $\mathrm{AlO}(\bullet)$. The $50 / 50$, aluminum / photoresist patterned surface is denoted by $\mathrm{Al} / \mathrm{PR}(\boldsymbol{\nabla})$. The blanket photoresist surface is denoted by PR (ם). The source power was $1100 \mathrm{~W}$, bias power was $200 \mathrm{~W}$, pressure was 10 mTorr, and the $\mathrm{Cl}_{2} / \mathrm{BCl}_{3}$ ratio was $100 / 40$.

Fig. 7 Electron (a) and negative ion (b) density as a function of additional argon flow rate for several wafer surface materials. The aluminum surface is denoted by $\mathrm{Al}(\bullet)$. The alumina surface is denoted by AlO ( $\bullet$ ). The $50 / 50$, aluminum / photoresist patterned surface is denoted by $\mathrm{Al} / \mathrm{PR}(\boldsymbol{\nabla})$. The blanket photoresist surface is denoted by PR (D). The source power was $900 \mathrm{~W}$, bias power was $185 \mathrm{~W}$, pressure was $7 \mathrm{mTorr}, \mathrm{Cl}_{2}$ flow rate was $60 \mathrm{sccm}$ and the $\mathrm{BCl}_{3}$ flow rate was 30 sccm. 


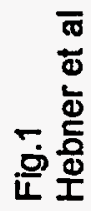

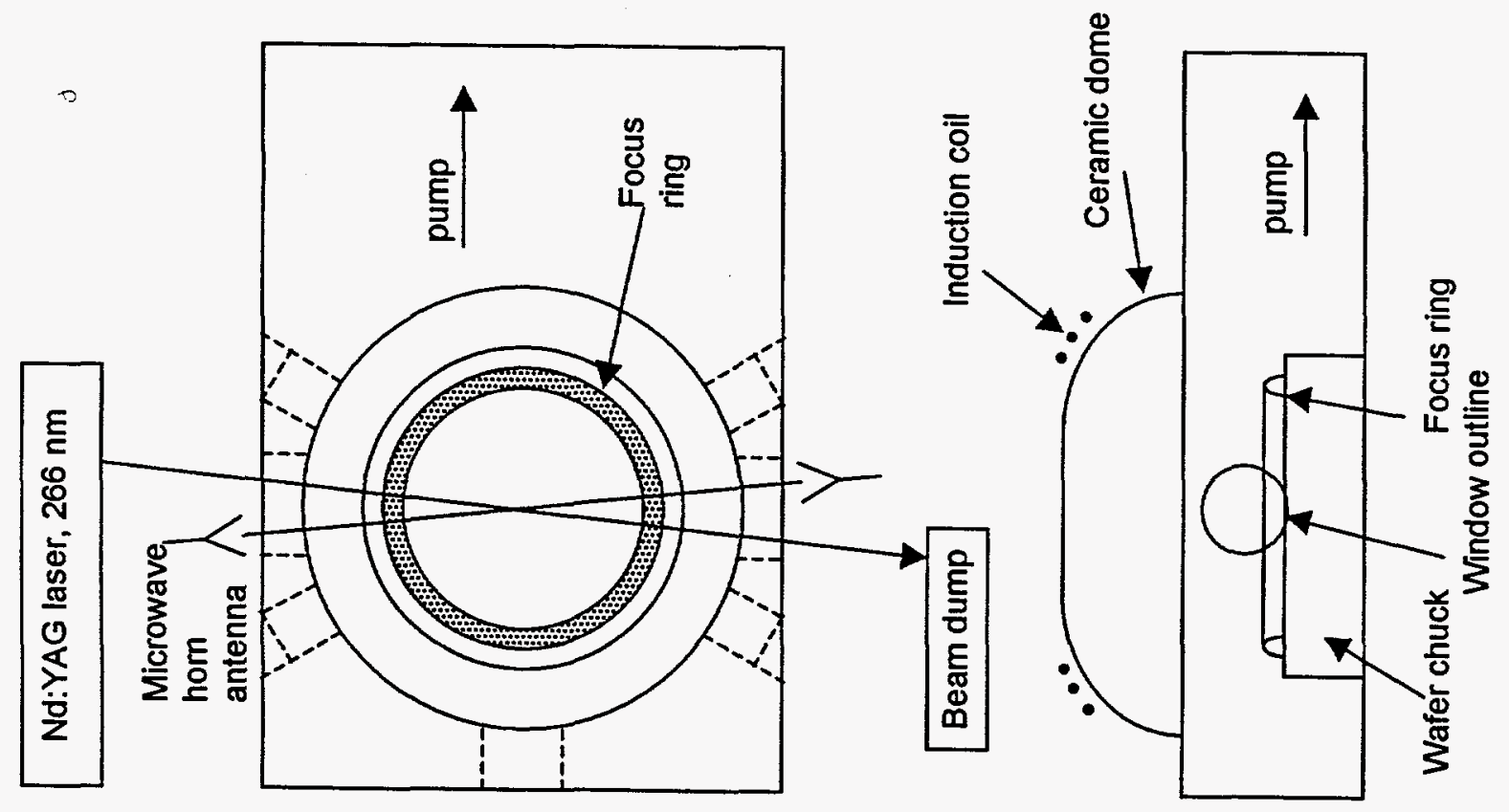



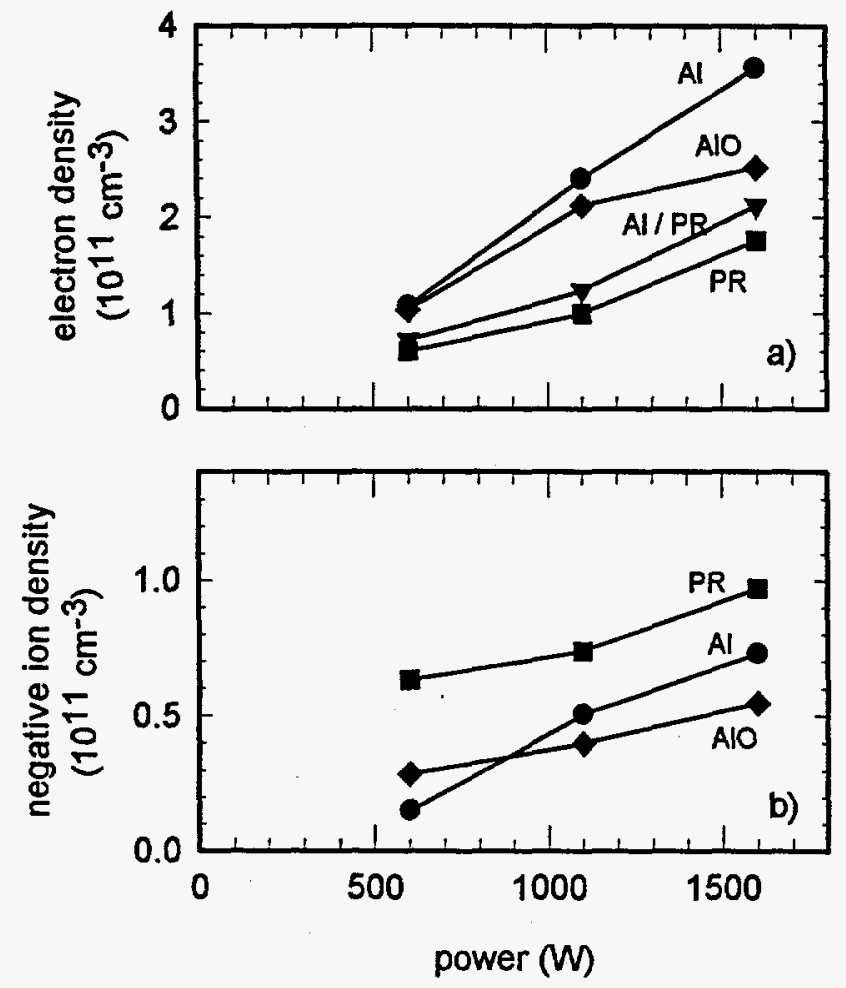

Fig. 2

Hebner et al 

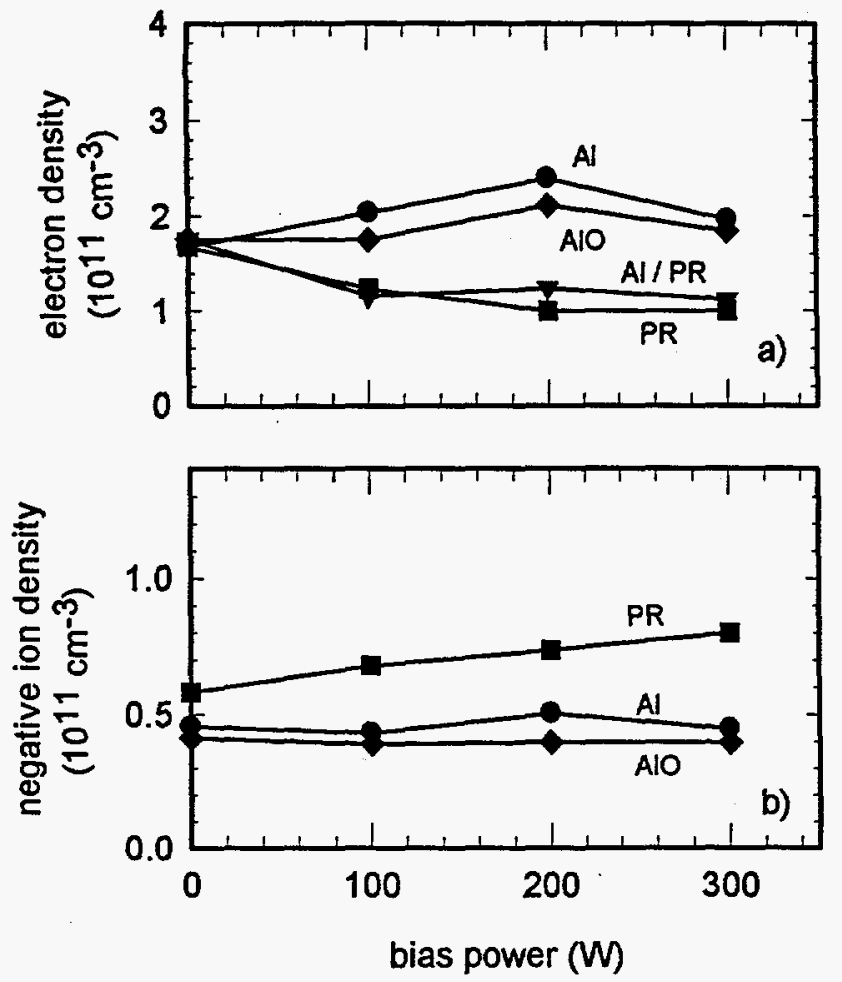

Fig. 3

Hebner et al 

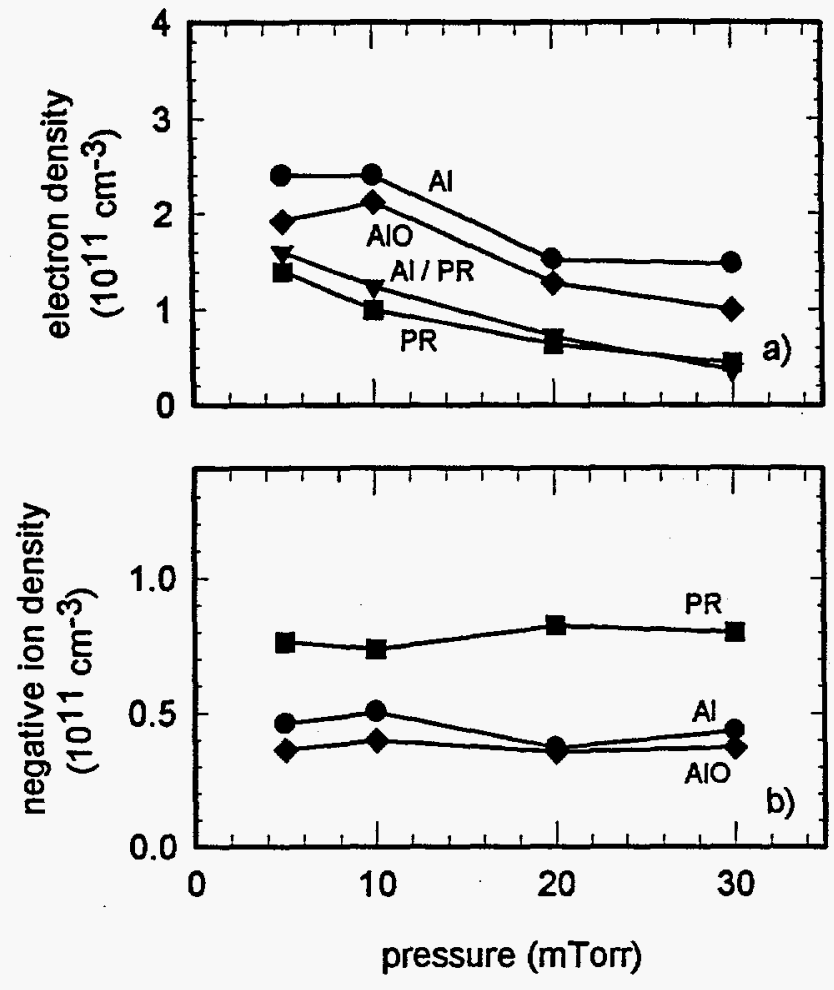

Fig. 4

Hebner et al 

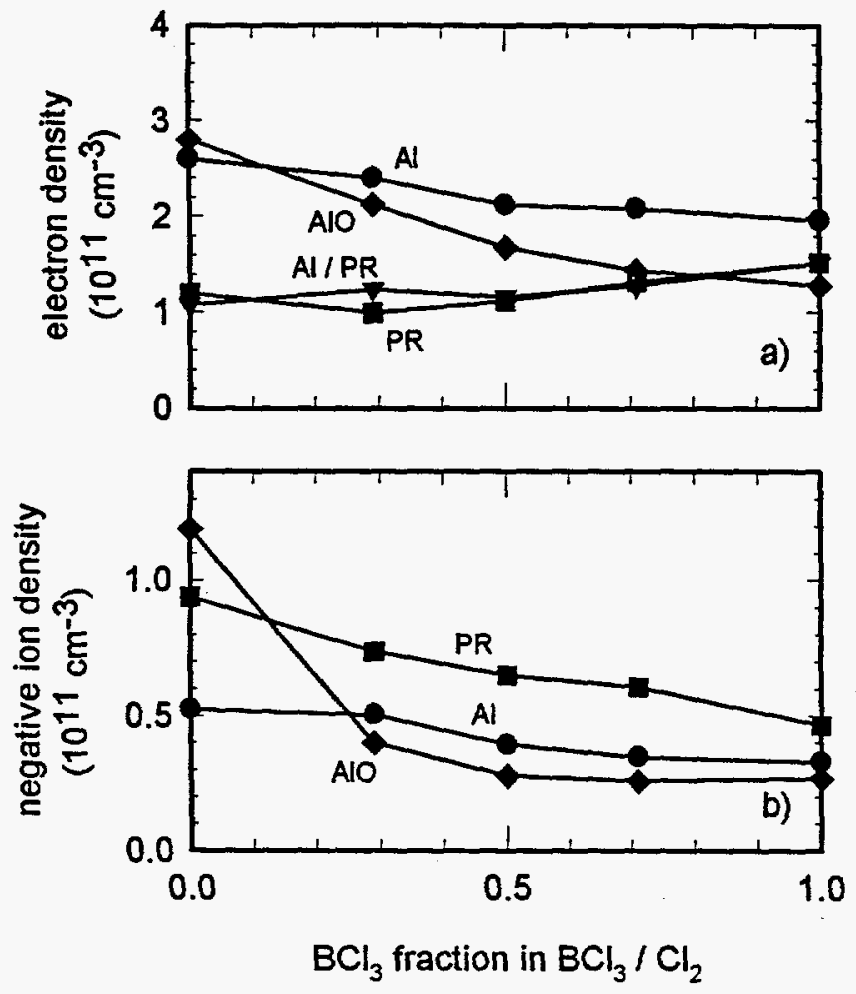

Fig. 5

Hebner et al 

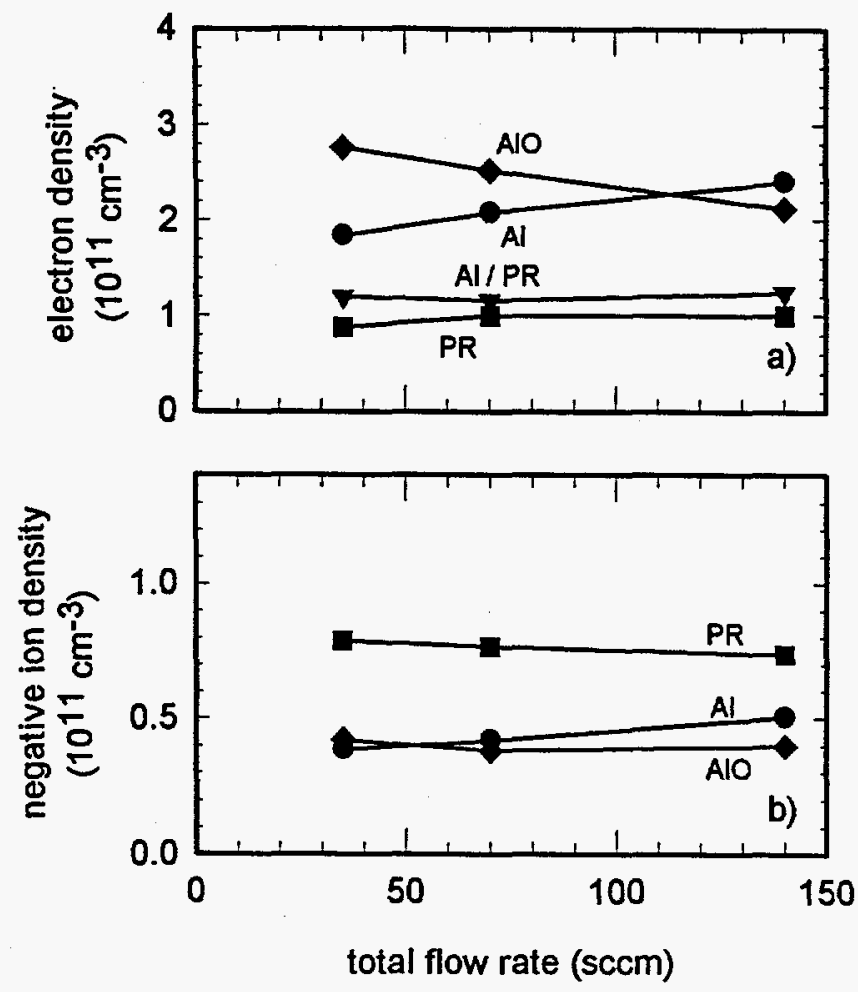

Fig. 6

Hebner et al 

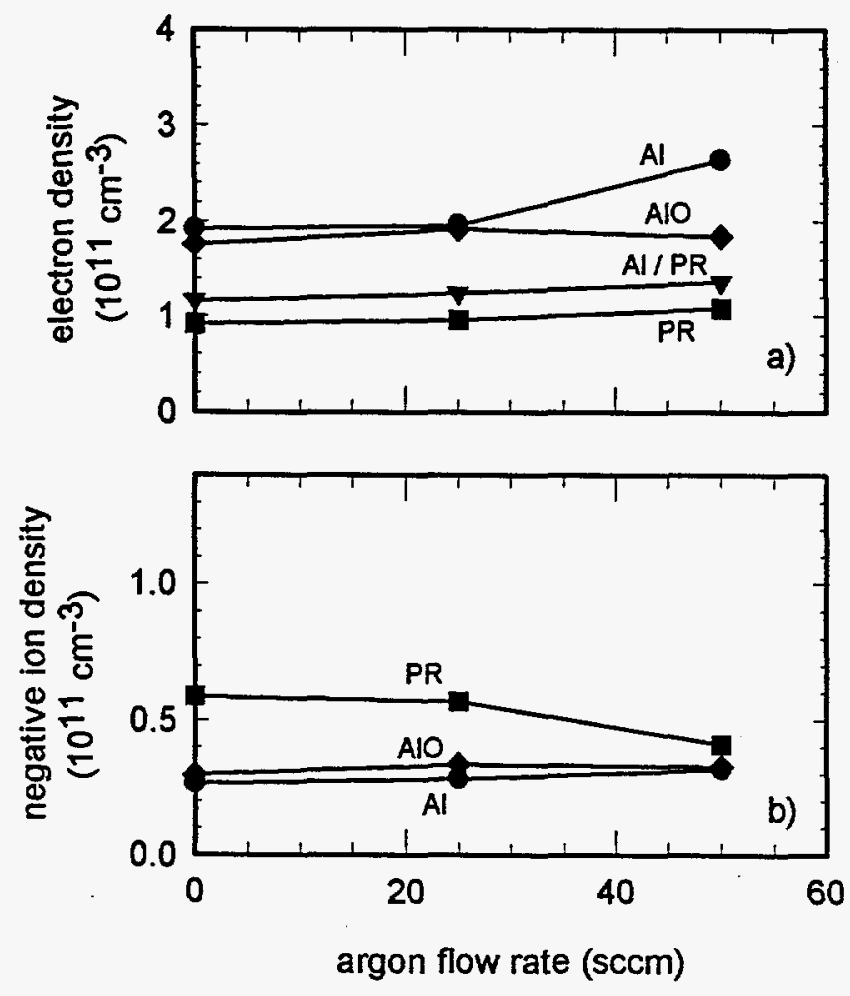

Fig. 7

Hebner et al 